\title{
Surgical management of acute cholecystitis: results of a 2-year prospective multicenter survey in Belgium
}

\author{
Benoit Navez $\cdot$ Felicia Ungureanu $\cdot$ Martens Michiels $\cdot$ Donald Claeys $\cdot$ \\ Filip Muysoms · Catherine Hubert • Marc Vanderveken • Olivier Detry • \\ Bernard Detroz $\cdot$ Jean Closset $\cdot$ Bart Devos $\cdot$ Marc Kint $\cdot$ Julie Navez $\cdot$ \\ Francis Zech · Jean-François Gigot · The Belgian Group for Endoscopic Surgery (BGES) \\ and the Hepatobiliary and Pancreatic Section (HBPS) of the Royal Belgian Society of Surgery
}

Received: 24 March 2011/ Accepted: 27 January 2012/Published online: 10 March 2012

(C) Springer Science+Business Media, LLC 2012

\begin{abstract}
Background Laparoscopic cholecystectomy is considered nowadays as the standard management of acute cholecystitis (AC). However, results from multicentric studies in the general surgical community are still lacking.

Methods A prospective multicenter survey of surgical management of AC patients was conducted over a 2-year period in Belgium. Operative features and patients' clinical outcome were recorded. The impact of independent predictive factors on the choice of surgical approach, the risk of conversion, and the occurrence of postoperative
\end{abstract}

B. Navez $(\bowtie) \cdot$ C. Hubert $\cdot$ J. Navez $\cdot$ F. Zech $\cdot$ J.-F. Gigot Department of Abdominal Surgery and Transplantation, Cliniques Universitaires Saint-Luc, Avenue Hippocrate, 10, 1200 Brussels, Belgium

e-mail: benoit.navez@uclouvain.be

F. Ungureanu $\cdot$ M. Michiels

Hôpital Saint-Joseph, Gilly, Belgium

D. Claeys · F. Muysoms

AZ Middelaeres, Gent, Belgium

M. Vanderveken

AZ Middelheim, Antwerpen, Belgium

O. Detry $\cdot$ B. Detroz

CHU du Sart Tilman, Liège, Belgium

J. Closset

Hôpital Erasme, Brussels, Belgium

B. Devos

AZ Onze Lieve Vrouw Ter Linden, Knokke, Belgium

M. Kint

AZ St Lucas, Ghent, Belgium complications was studied by multivariate logistic regression analysis.

Results Fifty-three surgeons consecutively and anonymously included 1,089 patients in this prospective study. A primary open approach was chosen in 74 patients $(6.8 \%)$, whereas a laparoscopic approach was the first option in 1,015 patients (93.2\%). Independent predictive factors for a primary open approach were previous history of upper abdominal surgery [odds ratio (OR) 4.13, $p<0.001$ ], patient age greater than 70 years (OR 2.41, $p<0.05$ ), surgeon with more than 10 years' experience (OR 2.08, $p=0.005$ ), and gangrenous cholecystitis (OR 1.71, $p<0.05)$. In the laparoscopy group, 116 patients $(11.4 \%)$ required conversion to laparotomy. Overall, 38 patients (3.5\%) presented biliary complications and 49 had other local complications $(4.5 \%)$. Incidence of bile duct injury was $1.2 \%$ in the whole series, $2.7 \%$ in the open group, and $1.1 \%$ in the laparoscopy group. Sixty patients had general complications (5.5\%). The overall mortality rate was $0.8 \%$. All patients who died were in poor general condition [American Society of Anesthesiologists (ASA) III or IV]. Conclusions Although laparoscopic cholecystectomy is currently considered as the standard treatment for acute cholecystitis, an open approach is still a valid option in more advanced disease. However, overall mortality and incidence of bile duct injury remain high.

Keywords Gallstone - Acute cholecystitis . Laparoscopy $\cdot$ Bile duct injury $\cdot$ Complications

Surgical management of patients suffering from acute cholecystitis (AC) includes early or delayed cholecystectomy and in selected high-risk patients percutaneous cholecystostomy. Because of its safety and shortened hospital 
stay, early laparoscopic cholecystectomy (LC) has come to be considered the standard treatment of AC [1-3]. Although an open approach remains a valid option in complicated cases (e.g., gangrenous cholecystitis, etc.), LC is reportedly safe and beneficial according to most series [4-8]. As the latter are issued from experts, they may not reflect general surgical practice, in particular regarding overall mortality and biliary complication rate. The Belgian Group for Endoscopic Surgery (BGES) therefore conducted a prospective national survey among the general community of surgeons in Belgium concerning the surgical approach of AC, feasibility and results of LC in an acute setting, as well as predictive factors of success of the laparoscopic approach.

\section{Patients and methods}

\section{Study design}

A prospective multicentric study was conducted over a 2-year period among members of the Belgian Group for Endoscopic Surgery and the Royal Belgian Society of Surgery concerning surgical management of patients suffering from AC in Belgium. The study was designed as open inclusion of all consecutive AC patients with a view to analyzing common practice, results of each surgical approach, predictive factors of mortality, morbidity (including bile duct injury), and conversion rate of general surgeons in Belgium.

Preliminary hypotheses included that:

1. Laparoscopy was the primary approach for operating AC

2. Conversion rate was significant (estimated range 10-20\%)

3. The rate of bile duct injury (BDI) was also significant (estimated above $0.5 \%$ ), in reference to a previous national survey [9]

There were 86 participating surgeons, 53 (62\%) of whom accepted to include their consecutive AC patients into the study. A total of 35 hospitals were involved, including 7 academic and 28 peripheral hospitals. A detailed questionnaire was used for each patient, and a computerized database was created. To improve the quality of data self-reported by the participating surgeons, anonymous data inclusion was guaranteed by the scientific coordinator of the study. Each participating surgeon could furthermore view his own results in comparison with the whole series but had no access to results of other surgeons.

Definition of variables

Diagnosis of AC was based on preoperative clinical features (fever, acute right upper quadrant abdominal pain with tenderness or guarding, and/or inflammatory mass), biological features [C-reactive protein (CRP) greater than $0.8 \mathrm{mg} / \mathrm{dl}$ and/or white blood cell count (WBCC) greater than $10.000 / \mathrm{mm}^{3}$ ], ultrasonographic features (positive sonographic Murphy sign and gallbladder wall thickness $>4 \mathrm{~mm}$ and/or pericholecystic fluid), along with confirmation of AC by the surgeon during surgical exploration. At final pathological examination, the following criteria were considered for the diagnosis of AC: mucosal and transmural infiltration of polymorphonuclear neutrophils with alteration of the mucosa such as necrosis or hemorrhage. Severity of AC was based on intraoperative pathological features. Edematous cholecystitis was defined as gallbladder wall edema and hyperemia, empyema as a pusfilled gallbladder with acutely inflamed and suppurative walls, and gangrenous cholecystitis as frank necrosis/gangrene of the gallbladder wall [10].

Study data analysis was based on variables relating to the patient, disease history, surgeon, and surgical procedure. Patient-related variables included age, sex, comorbidity according to American Society of Anesthesiologists (ASA) physical score, and previous history of upper abdominal surgery. Disease-related variables included clinical parameters such as type and duration of conservative medical treatment before LC, history of stone migration, presence of associated common bile duct stones (CBDS), need for preoperative endoscopic sphincterotomy (ES), biological parameters (e.g., CRP, WBCC), and pathological parameters (edematous or gangrenous cholecystitis, empyema). Surgeon-related variables included overall surgical experience (defined as surgical practice duration since certification) and laparoscopic experience with LC (defined as number of operated LC). Surgical procedure-related variables included the "intent-to-treat" type of approach (primarily open or laparoscopic), delay between first symptoms of $\mathrm{AC}$ and the operation, performance and results of intraoperative cholangiography (IOC), presence of CBDS or biliary anomaly at IOC, performance of subtotal cholecystectomy, need for conversion to open approach, and finally use of biliary or peritoneal drainage.

\section{Definition of endpoints}

Evaluation criteria included conversion rate, hospital mortality, complication rates (overall, local, and general), mean operating time, length of postoperative hospital stay, and need for reoperation or hospital readmission. Local complications included bile duct injury (BDI), biliary fistula, intraabdominal bleeding or abscess, and wound complications (evisceration, abscess, hematoma, etc.). BDI was defined as any injury to the main biliary tree; postoperative biliary fistula was defined as biliary leakage from an accessory bile duct (cystic or Luschka ducts). General 
complications included urinary complications (cystitis, retention), cardiac complications (failure, infarction), pulmonary complications (infection, acute respiratory distress syndrome), deep/superficial venous thrombosis, renal insufficiency, delirium, upper gastrointestinal (GI)-tract hemorrhage, etc. All evaluation criteria were assessed within a postoperative period of 3 months. No further follow-up was available.

\section{Statistical analysis}

Comparison of continuous variables was made using variance analysis, Student's $t$ test, logarithmic transformation or the Wilcoxon test when distribution was not normal. A chi-square test was used for comparison of proportions. A $p$ value $<0.05$ was considered statistically significant. The impact of each variable, such as independent predictive factors, on the type of approach, conversion, postoperative hospital stay, mortality, postoperative complications (local and general), bile duct injury, and fistula was tested using multivariate logistic regression. All covariates were introduced into the model.

\section{Results}

Analysis of patient groups

In total, 1,089 consecutive patients suffering from $\mathrm{AC}$ took part in the present study. Clinical, biological, diseaserelated, surgeon-related, and surgical procedure-related features of the whole series are presented in Table 1. The results were analyzed according to each treatment option. A primary open approach for cholecystectomy was chosen in 74 patients (6.8\%) (open group, OG) and an intent-totreat laparoscopic approach was the first option in 1,015 patients (laparoscopic group, LG) (93.2\%) (Table 2). Cholecystectomy was successfully accomplished by laparoscopy in 899 of 1,015 patients $(88.6 \%)$ (successful laparoscopic group, SLG). Conversion to open approach was required in 116 patients (11.4\%) (converted group, CG) (Table 3). Finally, pre- and perioperative features were analyzed according to the delay between the onset of AC and surgery (Table 4). Pathological examination of the specimen was obtained for 1,033 patients. The gallbladder specimens were mostly reported to show signs of edematous cholecystitis in 730 cases $(70.7 \%)$, of gangrenous cholecystitis $(n=259,25.1 \%)$, and empyema $(n=43$, $4.2 \%)$. There were significantly more cases with empyema and gangrenous cholecystitis in the OG $(31 / 74,41.9 \%)$ than in the LG $(271 / 958,28.3 \%)(p=0.013)$ (Table 2). There was one gallbladder carcinoma.
Table 1 Patients' clinical, biological, and disease-related, surgeonrelated, and surgical procedure-related features of the whole series of 1,089 patients operated for acute cholecystitis

\begin{tabular}{|c|c|}
\hline \multicolumn{2}{|l|}{ Clinical features } \\
\hline Number of patients & 1,089 \\
\hline Sex ratio $(F / M)$ & $1.35(626 / 463)$ \\
\hline Age, mean $\pm \mathrm{SD}$ (years) & $61.9 \pm 15.7$ \\
\hline ASA score III and IV & $175(16.1 \%)$ \\
\hline $\begin{array}{l}\text { Previous history of upper } \\
\text { abdominal surgery }\end{array}$ & $119(10.9 \%)$ \\
\hline History of stone migration & $201(18.5 \%)$ \\
\hline Coexistent CBDS & $75(6.9 \%)$ \\
\hline Need for ERC and ES & $246(22.6 \%)$ \\
\hline \multicolumn{2}{|l|}{ Biological features } \\
\hline $\mathrm{CRP}$, mean $\pm \mathrm{SD}(\mathrm{mgr} / \mathrm{dl})$ & $10.1 \pm 12.3$ \\
\hline $\mathrm{WBCC}$, mean $\pm \mathrm{SD}\left(\times 10^{3} / \mathrm{mm}^{3}\right)$ & $12.1 \pm 8.4$ \\
\hline \multicolumn{2}{|l|}{ Disease-related features } \\
\hline Need for percutaneous cholecystostomy & $11(1 \%)$ \\
\hline $\begin{array}{l}\text { Duration of initial medical } \\
\text { treatment, mean } \pm \mathrm{SD} \text { (days) }\end{array}$ & $4.7 \pm 8.9$ \\
\hline Edematous cholecystitis at pathology & $730(70.7 \%)$ \\
\hline Gangrenous cholecystitis at pathology & $259(25.1 \%)$ \\
\hline Empyema & $43(3.9 \%)$ \\
\hline \multicolumn{2}{|l|}{ Surgeon-related features } \\
\hline $\begin{array}{l}\text { Overall surgeon experience, } \\
\text { mean } \pm \mathrm{SD} \text { (years) }\end{array}$ & $11.1 \pm 7.3$ \\
\hline \multicolumn{2}{|l|}{ Laparoscopic experience with LC } \\
\hline$<100$ cases & $95(8.7 \%)$ \\
\hline $100-500$ cases & $286(26.3 \%)$ \\
\hline$>500$ cases & $708(65.0 \%)$ \\
\hline \multicolumn{2}{|l|}{ Surgical procedure-related features } \\
\hline \multicolumn{2}{|l|}{ Delay of surgery: } \\
\hline Operation within 4 days & $492(46.6 \%)$ \\
\hline Operation between 4 days and 6 weeks & $351(33.3 \%)$ \\
\hline Operation after 6 weeks & $212(20.1 \%)$ \\
\hline Primary open approach & $74(6.8 \%)$ \\
\hline Primary laparoscopic approach & $1,015(93.2 \%)$ \\
\hline Operative time, mean $\pm \mathrm{SD}(\min )$ & $87 \pm 38$ \\
\hline $\begin{array}{l}\text { Need for conversion } \\
\text { of LC to open approach }\end{array}$ & $116(11.4 \%)$ \\
\hline IOC performance & $545(50.0 \%)$ \\
\hline CBDS at IOC & $75(13.8 \%)$ \\
\hline Biliary anomaly at IOC & $27(2.6 \%)$ \\
\hline Subtotal cholecystectomy & $29(2.7 \%)$ \\
\hline Biliary drainage & $48(4.4 \%)$ \\
\hline Abdominal drainage & $833(76.5 \%)$ \\
\hline
\end{tabular}

$A C$ acute cholecystitis, ASA American Society of Anesthesiologists, $C B D S$ common bile duct stone, $C R P$ C-reactive protein, $E R C$ endoscopic retrograde cholangiography, $E S$ endoscopic sphincterotomy, $I O C$ intraoperative cholangiography, $L C$ laparoscopic cholecystectomy, $S D$ standard deviation, $W B C C$ white blood cell count 
Table 2 Patients' clinical, biological, and disease-related, surgeon-related, and surgical procedure-related variables in patients operated on primarily through open (OG) or laparoscopic approach (LG)

$A C$ acute cholecystitis, $A S A$ American Society of Anesthesiologists, $C B D S$ common bile duct stone, $C R P$ $\mathrm{C}$-reactive protein, $E R C P$ endoscopic retrograde cholangiography, ES endoscopic sphincterotomy, $I O C$ intraoperative cholangiography, $L C$ laparoscopic cholecystectomy, $N S$ not significant, $S D$ standard deviation, $W B C C$ white blood cell count

Choice of surgical approach

Although most patients $(708 / 1,089)$ were operated upon by experienced surgeons (>500 LC), 286 (26.3\%) were operated by surgeons having performed between 100 and 500 LC, and 95 patients $(8.7 \%)$ by surgeons having fewer than 100 LC. Univariate statistical comparison of patientrelated, disease-related, surgeon-related, and surgical procedure-related variables between OG and LG is detailed in Table 2. The OG included more males, older patients with higher operative risk, more patients with previous history of upper abdominal surgery, more associated CBDS, and

Clinical features

Number of patients

Sex ratio $(\mathrm{F} / \mathrm{M})$

ASA score III and IV

Associated CBDS

Need for ERC and ES

Biological features

$\mathrm{CRP}$, mean $\pm \mathrm{SD}(\mathrm{mgr} / \mathrm{dl})$

Disease-related features

Surgeon-related features

Delay of surgery:

Operation within 4 days

Operation after 6 weeks

IOC performance

CBDS at IOC

Biliary anomaly at IOC

Biliary drainage

$\begin{array}{lll}\begin{array}{l}\text { Open } \\ \text { group }(\mathrm{OG})\end{array} & \begin{array}{l}\text { Laparoscopic } \\ \text { group (LG) }\end{array} & p \text {-Value }\end{array}$

74

$0.72(31 / 43)$

1,015

$71.49 \pm 16.63$

$1.4(595 / 420) \quad 0.005$

$22(29.7 \%)$

$62.43 \pm 16.02$

$<0.001$

$23(31.1 \%)$

$153(15.1 \%)$

0.009

History of previous upper abdominal surgery

$18(24.3 \%)$

$96(9.5 \%)$

$<0.001$

$11(14.9 \%)$

$183(18.0 \%)$

NS

$19(25.7 \%)$

$64(6.3 \%)$

0.005

$\mathrm{WBCC}$, mean $\pm \mathrm{SD}\left(\times 10^{3} / \mathrm{mm}^{3}\right)$

$13.8 \pm 12.7$

$9.1 \pm 11.7$

$12.8 \pm 6.9$

$11.2 \pm 5.2$

0.013

$4(5.4 \%)$

$7(0.7 \%)$

$<0.001$

Edematous cholecystitis at pathology

$4.7 \pm 8.9$

NS

$43(58.1 \%)$

$687(71.7 \%)$

0.01

$31(41.9 \%)$

$271(28.3 \%)$

0.013

$12.9 \pm 7.3 \quad 11.1 \pm 7.3 \quad$ NS

$13(17.6 \%) \quad 82(8.1 \%) \quad 0.005$

$14(18.9 \%) \quad 272(26.8 \%) \quad$ NS

$47(63.5 \%) \quad 661(65.1 \%) \quad$ NS

Surgical procedure-related features

Operation between 4 days and 6 weeks

Operative time, mean \pm SD (min)

Need for conversion of LC to open approach

\begin{tabular}{lll}
$35(47.3 \%)$ & $457(46.6 \%)$ & NS \\
$34(45.9 \%)$ & $316(32.2 \%)$ & 0.015 \\
$5(6.8 \%)$ & $207(21.1 \%)$ & 0.003 \\
$98.27 \pm 41.77$ & $86.47 \pm 37.42$ & 0.001 \\
- & $116(11.4 \%)$ & - \\
$38(51.3 \%)$ & $507(49.9 \%)$ & NS \\
$11(28.9 \%)$ & $64(12.6 \%)$ & 0.005 \\
$13(34.2 \%)$ & $14(2.8 \%)$ & $<0.001$ \\
$4(5.4 \%)$ & $25(2.5 \%)$ & NS \\
$13(17.6 \%)$ & $35(3.4 \%)$ & $<0.001$ \\
$72(97.3 \%)$ & $761(74.9 \%)$ & $<0.001$ \\
\hline
\end{tabular}

more severe cholecystitis. In the OG, patients were more frequently treated preoperatively by percutaneous cholecystostomy and operated upon by surgeons having performed fewer than $100 \mathrm{LC}$, most often at a delay between 4 days and 6 weeks, and by using more frequently biliary or abdominal drainage. Independent predictive factors of primary open approach were found on multivariate analysis to be the following: previous history of upper abdominal surgery [OR 4.13, confidence interval (CI) 2.35-7.23, $p<0.001$ ], patient age more than 70 years (OR 2.41, CI $1.44-4.01, p<0.05)$, surgeons with more than 10 years' experience (OR 2.08, CI 1.24-3.49, $p=0.005$ ), and 
Table 3 Clinical, biological, disease-related, surgeon-related, and surgical procedure-related features of patients successfully treated by laparoscopy (SLG) or converted to laparotomy (CG)
$A C$ acute cholecystitis, $A S A$

American Society of

Anesthesiologists, $C B D S$

common bile duct stone, $C R P$

C-reactive protein, $E R C P$

endoscopic retrograde

cholangiography, ES

endoscopic sphincterotomy,

$I O C$ intraoperative

cholangiography, $L C$

laparoscopic cholecystectomy,

$N S$ not significant, $S D$ standard

deviation, $W B C C$ white blood cell count

\begin{tabular}{|c|c|c|c|}
\hline & $\begin{array}{l}\text { Successful } \\
\text { laparoscopic } \\
\text { group (SLG) }\end{array}$ & $\begin{array}{l}\text { Converted } \\
\text { group }(\mathrm{CG})\end{array}$ & $p$-Value \\
\hline \multicolumn{4}{|l|}{ Clinical features } \\
\hline Number of patients & 899 & 116 & \\
\hline Sex ratio $(F / M)$ & $1.55(547 / 352)$ & $0.7(48 / 68)$ & $<0.001$ \\
\hline Age, mean $\pm \mathrm{SD}$ (years) & $61.79 \pm 16.14$ & $67.39 \pm 14.6$ & $<0.001$ \\
\hline ASA score III and IV & $131(14.6 \%)$ & $22(18.9 \%)$ & NS \\
\hline Previous upper abdominal surgery & $79(8.8 \%)$ & $17(14.7 \%)$ & 0.04 \\
\hline History of stone migration & $151(16.8 \%)$ & $32(27.6 \%)$ & 0.004 \\
\hline Associated CBDS & $51(5.7 \%)$ & $13(11.2 \%)$ & 0.021 \\
\hline Need for ERC and ES & $194(21.6 \%)$ & $33(28.5 \%)$ & NS \\
\hline \multicolumn{4}{|l|}{ Biological features } \\
\hline $\mathrm{CRP}$, mean $\pm \mathrm{SD}(\mathrm{mgr} / \mathrm{dl})$ & $8.73 \pm 11.48$ & $12.54 \pm 12.67$ & $<0.001$ \\
\hline $\mathrm{WCC}$, mean $\pm \mathrm{SD}\left(\times 10^{3} / \mathrm{mm}^{3}\right)$ & $11.715 \pm 7.026$ & $11.509 \pm 6.392$ & NS \\
\hline \multicolumn{4}{|l|}{ Disease-related features } \\
\hline Percutaneous cholecystostomy & $7(0.8 \%)$ & 0 & NS \\
\hline Duration of initial medical treatment, mean \pm SD (days) & $4.7 \pm 8.9$ & $5.1 \pm 8.9$ & NS \\
\hline Edematous cholecystitis at pathology & $624(69.3 \%)$ & $62(53.9 \%)$ & $<0.001$ \\
\hline Gangrenous cholecystitis at pathology & $222(24.7 \%)$ & $51(44.3 \%)$ & $<0.001$ \\
\hline \multicolumn{4}{|l|}{ Surgeon-related features } \\
\hline Overall surgeon experience, mean $\pm \mathrm{SD}$ (years) & $15.53 \pm 19.41$ & 13.267 .31 & NS \\
\hline \multicolumn{4}{|l|}{ Laparoscopic experience with LC } \\
\hline$<100$ & $59(6.6 \%)$ & $23(19.8 \%)$ & $<0.001$ \\
\hline $100-500$ & $238(26.5 \%)$ & $34(29.3 \%)$ & NS \\
\hline$>500$ & $603(67.1 \%)$ & $58(50.0 \%)$ & NS \\
\hline \multicolumn{4}{|l|}{ Surgical procedure-related features } \\
\hline $\begin{array}{l}\text { Delay between first symptoms of } \mathrm{AC} \text { and operation, } \\
\text { mean } \pm \mathrm{SD} \text { (days) }\end{array}$ & $18.6 \pm 48.1)$ & $18.7 \pm 24.8$ & NS \\
\hline Operative time, mean $\pm \mathrm{SD}(\min )$ & $82.04 \pm 33.90$ & $121.50 \pm 44.37$ & $<0.001$ \\
\hline IOC performance & $462(51.4 \%)$ & $45(38.8 \%)$ & 0.01 \\
\hline CBDS at IOC & $51(5.7 \%)$ & $13(11.2 \%)$ & 0.02 \\
\hline Biliary anomaly at IOC & $12(1.3 \%)$ & $2(1.7 \%)$ & NS \\
\hline Subtotal cholecystectomy & $16(1.8 \%)$ & $9(7.8 \%)$ & $<0.001$ \\
\hline Biliary drainage & $23(2.6 \%)$ & $12(10.3 \%)$ & $<0.001$ \\
\hline Abdominal drainage & $653(72.6 \%)$ & $108(93.1 \%)$ & $<0.001$ \\
\hline
\end{tabular}

presence of gangrenous cholecystitis (OR 1.71, CI 1.01-2.89, $p<0.05)$.

Timing of surgical approach

Fifty-four percent of the patients $(586 / 1,089)$ received antibiotics prior to cholecystectomy during a variable period of time (mean $4.7 \pm 8.9$ days). Seventy percent of patients had antibiotics in the preoperative period in the CG (81/116 patients) and $51 \%$ in the SLG (461/899) $(p<0.001)$. There was no significant correlation between duration of antibiotic therapy and risk of conversion or complications.
Information about the delay between the first symptoms of AC and operation was obtained for 1,055 patients. Early operation, i.e., within 4 days, was performed for 492 patients (46.6\%), whereas 351 patients $(33.3 \%)$ had cholecystectomy 4 days to 6 weeks after initial AC symptoms, and $212(20.1 \%)$ had delayed operation (after 6 weeks). Preoperative percutaneous cholecystostomy was performed in 11 patients $(1.0 \%)$.

\section{Surgical procedure-related features}

Mean operating time was $98 \mathrm{~min}$ in the $\mathrm{OG}$ and $86 \mathrm{~min}$ in the LG $(p=0.001)$. IOC was performed in $50.0 \%$ of the 
Table 4 Comparison of early and 3-month postoperative outcome according to delay of operation

\begin{tabular}{|c|c|c|c|c|}
\hline & $\begin{array}{l}\text { Early operation } \\
\text { ( }<4 \text { days })\end{array}$ & $\begin{array}{l}\text { Operation between } \\
4 \text { days and } 6 \text { weeks }\end{array}$ & $\begin{array}{l}\text { Delayed operation } \\
\text { ( }>6 \text { weeks) }\end{array}$ & $p$ Value \\
\hline \multicolumn{5}{|l|}{ Early postoperative outcome } \\
\hline Mortality & $3 / 354(1.4 \%)$ & $3 / 382(0.8 \%)$ & $1 / 206(0.5 \%)$ & NS \\
\hline \multicolumn{5}{|l|}{ Complications } \\
\hline Overall & $48 / 411(11.7 \%)$ & $40 / 430(9.3 \%)$ & $16 / 213(7.5 \%)$ & NS \\
\hline Local & $21 / 411(5.1 \%)$ & $20 / 430(4.7 \%)$ & $8 / 213(3.75 \%)$ & NS \\
\hline General & $27 / 411(5.6 \%)$ & $20 / 430(4.7 \%)$ & $8 / 213(3.75 \%)$ & NS \\
\hline \multicolumn{5}{|l|}{ Biliary complications } \\
\hline Bile duct injury & $4 / 406(1.0 \%)$ & $7 / 426(1.6)$ & $2 / 212(0.9 \%)$ & NS \\
\hline Biliary fistula & $11 / 406(2.7 \%)$ & $10 / 426(2.3 \%)$ & $4 / 211(1.9 \%)$ & NS \\
\hline Postoperative hospital stay, mean \pm SD (days) & $8.75 \pm 26.55$ & $11.59 \pm 13.3$ & $27.22 \pm 40.61$ & NS \\
\hline \multicolumn{5}{|l|}{ 3-Month postoperative outcome } \\
\hline Readmission & $5 / 354(1.4 \%)$ & $13 / 390(3.3 \%)$ & $5 / 205(2.4 \%)$ & NS \\
\hline Reoperation & $5 / 354(1.4 \%)$ & $9 / 390(2.3 \%)$ & $3 / 205(1.5 \%)$ & NS \\
\hline
\end{tabular}

$N S$ not significant, $S D$ standard deviation

whole series (545/1,089), 51.4\% of SLG patients (462/ $899), 38.8 \%$ of CG patients (45/116), and $51.3 \%$ of OG patients $(38 / 74)$. Among the 545 patients who underwent IOC, biliary anomaly was found in 27 patients $(2.6 \%)$ and CBDS was present in 75 patients (13.8\%). However, 201 patients had clinical history of stone migration (18.5\%). Biliary drainage after CBD exploration was left in place in $4.4 \%$ (48/1,089). There were more cases with biliary drainage in the OG $(13 / 74,17.6 \%)$ than in the LG $(35 /$ $1,015,3.4 \%)(p<0.001)$. Abdominal drainage was placed in $76.5 \%$ of patients $(833 / 1,089)$, more frequently in the OG $(72 / 74,97.3 \%)$ than in the LG $(761 / 1,015,74.9 \%)$ $(p<0.001)$. Subtotal cholecystectomy was performed in $2.7 \%$ of patients $(29 / 1,089), 2.5 \%(25 / 1,015)$ in the LG, and $5.4 \%$ (4/74 patients) in the OG [not significant (NS)] (Table 2).

\section{Conversion to laparotomy}

Among the 1,015 patients, 116 patients required conversion to laparotomy (11.4\%), of whom 69 were males and 47 females. Conversion rate was $7.5 \%$ (47/626) for females and $14.9 \%$ (69/463) for males. Mean delay from pneumoperitoneum to conversion was $36 \mathrm{~min}$ (5-128 min). The reasons for conversion were, in decreasing frequency, unclear anatomy and technical difficulties in 67 patients $(57.8 \%)$, suspicion of BDI in $9(7.8 \%)$, bleeding in 8 (6.9\%), unsuccessful stone extraction in $6(5.2 \%)$, and suspicion of gallbladder carcinoma in 3 (2.6\%). Cancer was confirmed by pathological examination for only one case.

Clinical, biological, disease-related, surgeon-related, and surgical procedure-related features in the SLG and CG are presented in Table 3. In the CG, patients tended to be men, be older, and have previous upper abdominal surgery, associated CBDS, and more severe cholecystitis, and surgeons tended to be less experienced, took longer operating time, and made greater use of IOC as well as subtotal cholecystectomy, and biliary and peritoneal drainage. Multivariate analysis indicated that patients who had a significantly higher risk of being converted to laparotomy were those who had preoperative antibiotics (OR 1.91, CI $1.20-3.04, p=0.006$ ), gangrenous cholecystitis (OR 2.07, CI 1.34-3.21, $p=0.001$ ), and associated CBD stone migration (OR 1.99, CI 1.23-3.21, $p=0.005$ ). Conversion was also more frequent if the surgeon had less experience (fewer than 500 LC) (OR 2.65, CI 1.71-4.10, $p<0.001$ ).

Surgeons having more than 10 years' experience converted more frequently to laparotomy (OR 2.47, CI 1.57-3.9, $p<0.001)$. Women under 65 years of age were less at risk of requiring conversion (OR 0.26, CI $0.14-0.50, p<0.001$ ).

Mortality and complication rates

Early and late postoperative outcome in the OG and LG are reported in Table 5, as well as in the SLG and CG in Table 6. Thirty-eight patients $(3.5 \%)$ presented biliary complications: 5 patients in the OG (2 BDI and 3 biliary leaks) and 33 patients in the LG (11 BDI and 22 biliary leaks). Incidence of biliary complications was higher in the OG $(6.8 \%)$ than in the LG $(3.3 \%)$, but the difference was not significant $(p=0.07)$. Overall incidence of BDI was $1.2 \%(13 / 1,089)$. BDI was more frequent in OG patients $(2.7 \%, 2 / 74)$ than in the LG $(1.1 \%, 11 / 1,015)$, but the difference was not significant $(p=0.40)$. In the OG, there was one complete CBD transection and one partial injury 
Table 5 Comparison of early and 3-month postoperative outcome of patients operated primarily through open (OG) or laparoscopic approach (LG)

$N S$ not significant, $S D$ standard deviation

Table 6 Comparison of early and 3-month postoperative outcome of patients successfully operated using laparoscopic approach (SLG) or converted to open surgery $(\mathrm{CG})$

$N S$ not significant, $S D$ standard deviation

\begin{tabular}{llll}
\hline & $\begin{array}{l}\text { Open group (OG) } \\
N=74\end{array}$ & $\begin{array}{l}\text { Laparoscopic group (LG) } \\
N=1,015\end{array}$ & $p$ Value \\
\hline Early postoperative outcome & & & \\
Mortality (\%) & $4(5.4 \%)$ & $5(0.5 \%)$ & $<0.001$ \\
General complications (\%) & $3(4.1 \%)$ & $57(5.6 \%)$ & NS \\
Biliary complications (\%) & $5(6.8 \%)$ & $33(3.3 \%)$ & 0.07 \\
Bile duct injury & 2 & 11 & \\
Biliary fistula & 3 & 22 & 0.007 \\
Other local complications (\%) & $8(10.8 \%)$ & $41(4.0 \%)$ & 0.001 \\
Reoperation (\%) & $4(5.4 \%)$ & $10(1.0 \%)$ & 0.01 \\
Postoperative hospital stay, mean \pm SD (days) & $12.0 \pm 9.3$ & $6.0 \pm 13.3$ & \\
3-Month postoperative outcome & & & NS \\
Late complications $(\%)$ & $1(1.4 \%)$ & $17(1.7 \%)$ & NS \\
Readmission $(\%)$ & $2(2.7 \%)$ & $13(1.3 \%)$ & \\
\hline
\end{tabular}

\begin{tabular}{llll}
\hline & $\begin{array}{l}\text { Successful laparoscopic } \\
\text { group (SLG) } N=899\end{array}$ & $\begin{array}{l}\text { Converted group } \\
\text { (CG) } N=116\end{array}$ & $p$ Value \\
\hline $\begin{array}{l}\text { Early postoperative outcome } \\
\text { Mortality (\%) }\end{array}$ & $4(0.44 \%)$ & $1(0.08 \%)$ & NS \\
Overall complications (\%) & $106(11.79 \%)$ & $37(31.89 \%)$ & $<0.001$ \\
General complications (\%) & $48(5.33 \%)$ & $9(7.76 \%)$ & NS \\
Biliary complications (\%) & $17(1.89 \%)$ & $16(13.79 \%)$ & $<0.001$ \\
$\quad$ Bile duct injury (\%) & 4 & 7 & \\
$\quad$ Biliary fistula (\%) & 13 & 9 & $<0.001$ \\
Other local complications (\%) & $26(2.89 \%)$ & $15(12.93 \%)$ & NS \\
Reoperation (\%) & $8(0.89 \%)$ & $2(1.72 \%)$ & 0.03 \\
Postoperative hospital stay, mean \pm SD (days) & $5.5 \pm 13.8$ & $10.0 \pm 6.4$ & NS \\
3-Month postoperative outcome & & $3(2.58 \%)$ & NS \\
Late complications (\%) & $14(1.55 \%)$ & $2(1.72 \%)$ & \\
Readmission (\%) & $11(1.22 \%)$ & & \\
\hline
\end{tabular}

of the right hepatic duct. In the LG, there were two complete CBD transections and nine partial CBD injuries of which three occurred after conversion and four before conversion. Multivariate logistic regression analysis indicated that conversion was the only factor associated with BDI $(p<0.001)$.

Forty-nine patients $(4.5 \%)$ had other local complications including 31 wound complications, 7 intra-abdominal hemorrhages, 3 intra-abdominal abscesses, 7 residual CBD stones, and 1 biochemical pancreatitis. The wound complication rate was $10.8 \%(8 / 74)$ in the OG compared with $2.3 \%(23 / 1,015)$ in the LG $(p<0.001)$, and it was significantly lower in the SLG $(1.6 \%, 14 / 899)$ than in the CG $(7.8 \%, 9 / 116)(p<0.001)$. Predictive factors identified on multivariate logistic regression were associated CBD stone migration (OR 2.00, CI 1.03-3.87, $p=0.04$ ) and conversion (OR 3.94, CI 2.04-7.65, $p<0.01$ ).
Overall, 60 patients had general complications (5.5\%): cardiac failure $(n=3)$, myocardial ischemia (3), cardiac arrhythmia (2), pulmonary infections (11), pleural effusion (1), acute respiratory distress syndrome (ARDS) (1), stroke (2), deep/superficial vein thrombosis (3), renal failure (6), urinary infection (5), urinary retention (6), septicemia (4), hyperthermia (4), upper GI-tract hemorrhage (1), gastroenteritis (4), hepatitis (3), anemia (2), delirium (1), and others (4). The risk factors for general complications identified on multivariate logistic regression analysis were observed to be ASA score III or IV (OR 4.2, CI 4.40-7.68, $p<0.01$ ) and gangrenous cholecystitis (OR 3.0, CI $1.69-5.34, p<0.001)$.

Mortality rate was $0.8 \%$ overall $(9 / 1,089)$, all occurring in patients in poor general condition (ASA III or IV). The causes of death were sepsis $(n=4)$, multiple organ failure (2), cardiopulmonary dysfunction (2), and stroke and 
hemorrhage from the liver bed (1). Five patients died in the LG $(0.5 \%)$ and four in the OG $(5.4 \%)(p<0.001)$. Predictive factors of mortality were found on multivariate logistic regression to be occurrence of postoperative general complications and initial choice of open approach $(p<0.001)$.

Four of 74 OG patients (5.4\%) had to be reoperated, versus 10 of $1,015 \mathrm{LG}$ patients $(1.0 \%, p=0.001)$. There was no statistical difference concerning the reintervention rate between CG and SLG.

Mean postoperative hospital stay was $12.0 \pm 9.3$ days for OG patients and $6.0 \pm 13.3$ days for LG patients $(p=0.01)$. Mean postoperative hospital stay was $10.0 \pm 6.4$ days for the $C G$ and $5.5 \pm 13.8$ days for the SLG $(p=0.03)$.

At 3 months postoperatively, there was no statistical difference between the different groups (OG versus LG and SLG versus CG) in terms of either late complications or readmission rates. Finally, the delay between the first symptoms of AC and LC influenced neither the early mortality and complication rates nor the 3 -month outcome (Table 4).

\section{Discussion}

In this multicenter Belgian national survey, all patients were included consecutively, reflecting the common practice of general surgeons in Belgium rather than only the practice of expert centers. The choice between open and laparoscopic approach was left to the discretion of each of the 53 participating surgeons. Most importantly, the data were included anonymously, thereby improving the reliability of the results and providing a clear overall representative picture of surgical management of AC in Belgian hospitals.

In the present study, primary open cholecystectomy was chosen by surgeons for cases in which the patient was older, had a history of previous upper abdominal surgery, when gangrenous cholecystitis was suspected, and when surgeons had more than 10 years' experience. In the latter situation, primary open approach was probably considered as more careful practice. Additionally, surgeons having more than 10 years' experience and surgeons having performed fewer than $500 \mathrm{LC}$ converted more frequently. This could mean that, with experience, surgeons identified risks more rapidly during LC, while surgeons less skilled in laparoscopic techniques recognized that the laparoscopic approach might be technically too demanding in difficult cases of AC and preferred conversion to a primary open approach [3, 11-14]. Local disease-related factors, such as gangrenous cholecystitis or coexistent CBDS, were major predictive factors of conversion, in agreement with previous reports $[13,14]$. Surprisingly, women under the age of
65 years were less at risk of requiring conversion $(p<0.001)$. Whether this was because of cosmetic reasons or because men had a higher rate of complicated AC is unclear. Indeed, it has been reported that inflammation and fibrosis are more extensive in men than in women, which could explain a higher conversion rate [15]. Similarly, men and older patients have higher conversion and complication rates [16]. The overall conversion rate was $11.4 \%$ in the present study ( $7.5 \%$ for men and $14.9 \%$ for women), without increased mortality but with increased local complication rates and longer hospital stay.

In cases where a primary laparoscopic approach was chosen, there was no relationship between preoperative medical treatment and either conversion or complication rates, essentially because of a great variability in the delay before LC [standard deviation (SD): 8.9 days]. On the other hand, patients treated preoperatively with antibiotics (regardless of treatment duration) were at higher risk of requiring conversion. This may be linked to the fact that decision to give preoperative antibiotics may be related to disease severity. In their recent systematic review of randomized controlled trials, Gurusamy et al. report that there was no significant difference between early and delayed cholecystectomy for $\mathrm{AC}$ in terms of BDI or conversion to open cholecystectomy, although total hospital stay was shorter by 4 days in the early patient group. Furthermore, $17.5 \%$ of the patients who underwent the delayed surgical approach were operated as an emergency because of nonresolving or recurrent cholecystitis [2]. The overall complication rate was shown in a previous study to be statistically higher if the delay before operation was more than 4 days (19.8\% versus $13.3 \%)$, as was the local complication rate $(13.2 \%$ versus $6.5 \%)$ [4]. In the present survey, there was no difference in complication rate between early and delayed cholecystectomy groups. However, several meta-analyses and controlled trials recommend early operation for AC [2, 17, 18].

In the present study, overall incidence of BDI was, as expected, significantly higher (1.2\%) than in previously reported national surveys of LC. Nuzzo et al. reported in a multicenter national series an overall BDI incidence of $0.56 \%$ in cholecystitis, significantly higher than $0.32 \%$ in simple cholelithiasis [19]. In two other national multicenter studies including both acute and elective cases, BDI rates were 0.5 and $0.25 \%$, respectively [20, 21]. Cholecystitis must be considered as a risk factor for BDI, as shown by Gigot et al. in a previous national survey of 65 BDI in Belgium [9] in which AC and scleroatrophic gallbladder were present in half of patients. Because of the anonymous inclusion of patients in the present study, the BDI incidence of $1.2 \%$ is probably a closer reflection of reality. However, we must also take into consideration the significant rate of postoperative biliary fistula, which can hide 
some unrecognized BDI as reported in the literature. A key message from the present study is that, contrary to usual consideration, conversion to open approach during LC for $\mathrm{AC}$ is not a guarantee to avoid BDI, since three BDI occurred after conversion. This is important from the medicolegal point of view. On the contrary, four BDI were discovered during conversion while having occurred and been suspected during the laparoscopic phase of the operation. In $7.8 \%$ of the converted cases in the present series the reason was BDI suspicion.

The opinion of the surgical community regarding performance of IOC during LC is torn between the idea that routine IOC does not help prevent BDI [19] and the idea that the rate of CBD injury is significantly lower when IOC is used [21]. Like Suter et al., the authors believe that, especially in case of AC, IOC is strongly recommended because it helps to clarify the anatomy and allows early diagnosis and repair of BDI [9, 22].

Subtotal cholecystectomy has been reported as a good alternative to classic cholecystectomy to reduce the risk of BDI and conversion in patients with technically difficult operation for severe cholecystitis [23-27]. Surprisingly, in the current series, subtotal cholecystectomy was performed in only $2.7 \%$ of patients. In a study of 39 patients with severe cholecystitis and difficult local conditions, Hubert et al. reported the safety of the endovesicular approach with subtotal cholecystectomy for gallbladder dissection as an alternative to the classic Calot's triangle dissection. In their series there were no postoperative biliary or infectious complications [26].

In a randomized trial comparing open versus $\mathrm{LC}$ for $\mathrm{AC}$, Johansson et al. found no significant differences in the rate of postoperative complications [28]. In the present study, the wound infection rate was significantly higher in the OG than in the LG (10.8\% versus $2.3 \%)$. As reported by other authors [8], this may be due to the fact that patients treated by open surgery were significantly older, were at greater operative risk, and had more severe biliary disease than patients treated laparoscopically. According to our multivariate analysis, $\mathrm{CBD}$ stone migration and conversion to laparotomy were identified as risk factors for local complications. The passage of a stone through the cystic duct may produce inflammation or fibrosis in Calot's triangle, making identification of important anatomical landmarks more difficult and thereby increasing the risk of BDI, biliary fistula, bleeding, or conversion to laparotomy. The overall mortality rate was $0.8 \%$ in the present surgical series. All operated patients who died were in poor general condition with significant comorbidities (ASA III or IV). The mortality rate was significantly higher in the primary open approach but not in the converted group. Practically, $\mathrm{AC}$ remains a severe and potentially lethal disease [27, 29], especially in elderly and high-risk patients.
In conclusion, primary laparoscopic approach was considered by Belgian surgeons as the standard approach in 93.2\% of AC. Primary open approach or conversion remained alternative options. The conversion rate was as expected at $11.4 \%$ and was related to various patient, disease, and surgeon features. The risk of BDI in AC was high $(1.2 \%)$, and although the present survey was not comparative, this was higher than in a previous national Belgian survey. Finally, use of subtotal cholecystectomy is also a good option in case of dangerous dissection of a severely inflamed Calot's triangle.

Acknowledgments The following members of BGES are gratefully acknowledged for their substantial contributions to the present study: Drs. Jacques Baillieux (Hornu), Jean Beaurang (Willebroek), Michel Bourdon (Libramont), Emmanuel Cambier (Gilly), Bernard Dallemagne (Liège), Georges Decker (Luxembourg), Robert De Keulenner (Auvelais), Didier Deltour (Gosselies), Olivier Dockx (Marche), Raphael Droissart (Brussels), Mary-Lou Druart (deceased) (Brussels), Pierre Guiot (Gilly), Dominique Herman (Libramont), Jean-Luc Jourdan (Liège), Fadi Maassarani (Auvelais), Bernard Majerus (Ottignies), Baudouin Mansvelt (Jolimont), Pierre Mendes Da Costa (Brussels), Benoit Monami (Liège), Karel Mulier (Leuven), Christian Ngongang (Marche), Jacques Peeters (Waremme), Pascal Remy (Hornu), Casper Sommeling (Waregem), Pierre Taziaux (Malmedy), Musa Tugilimana (Ath), and Etienne Veys (Gosselies). The authors also wish to thank Prof $\mathrm{C}$. de Burbure for revising the manuscript.

Disclosures Authors Benoit Navez, Felicia Ungureanu, Martens Michiels, Julie Navez, Donald Claeys, Filip Muysoms, Catherine Hubert, Marc Vanderveken, Olivier Detry, Bernard Detroz, Jean Closset, Bart Devos, Marc Kint, Francis Zech, and Jean-François Gigot have no conflicts of interest or financial ties to disclose.

\section{References}

1. Sauerland S, Agresta F, Bergamachi R, Borzellino G, Budzynski A, Champault G, Fingerhut A, Isla A, Johansson M, Lundorff P, Navez B, Saad S, Neugebauer EA (2006) Laparoscopy for abdominal emergencies: evidence-based guidelines of the European Association for Endoscopic Surgery. Surg Endosc 20(1):14-29

2. Gurusamy K, Samraj K, Gluud C, Wilson E, Davidson BR (2010) Meta-analysis of randomized controlled trials on the safety and effectiveness of early versus delayed laparoscopic cholecystectomy for acute cholecystitis. Br J Surg 97(2):141-150

3. David GG, Al-Sarira AA, Willmott S, Deakin M, Corless DJ, Slavin JP (2008) Management of acute gallbladder disease in England. Br J Surg 95(4):472-476

4. Navez B, Mutter D, Russier Y, Vix M, Jamali F, Lipski D, Cambier E, Guiot P, Leroy J, Marescaux J (2001) Safety of laparoscopic approach for acute cholecystitis: retrospective study of 609 cases. World J Surg 25(10):1352-1356

5. Pessaux P, Tuech JJ, Rouge C, Duplessis R, Cervi C, Arnaud JP (2000) Laparoscopic cholecystectomy in acute cholecystitis. A prospective comparative study in patients with acute vs. chronic cholecystitis. Surg Endosc 14(4):358-361

6. Martin M, Abrams M, Arkin R, Ballen P, Blievernicht S, Bowman W, Davis T, Farley R, Hoxworth B, Ingram H, Lindsey A, Leone M, Newman D, Price T, Streck C, Weatherly W, Young P 
(1993) Safe laparoscopic cholecystectomy in a community setting, $N=762$. Surg Endosc 7(4):300-303

7. Kolla SB, Aggarwal S, Kumar A, Kumar R, Chumber S, Parshad R, Seenu V (2004) Early vs delayed laparoscopic cholecystectomy for acute cholecystitis: a prospective randomized trial. Surg Endosc 18(9):1323-1327

8. Glavic Z, Begic L, Simlesa D, Rukavina A (2001) Treatment of acute cholecystitis. A comparison of open vs laparoscopic cholecystectomy. Surg Endosc 15(4):398-401

9. Gigot J, Etienne J, Aerts R, Wibin E, Dallemagne B, Deweer F, Fortunati D, Legrand M, Vereecken L, Doumont J, Van Reepinghen P, Beguin C (1997) The dramatic reality of biliary tract injury during laparoscopic cholecystectomy. An anonymous multicenter Belgian survey of 65 patients. Surg Endosc 11(12): $1171-1178$

10. Fitzgibbons RJ Jr, Tseng A, Wang H, Ryberg A, Nguyen N, Sims KL (1996) Acute cholecystitis. Does the clinical diagnosis correlate with the pathological diagnosis? Surg Endosc 10(12):1180 1184

11. Schrenk P, Woisetschläger R, Rieger R, Wayand WU (1998) A diagnostic score to predict the difficulty of a laparoscopic cholecystectomy from preoperative variables. Surg Endosc 12(2): $148-150$

12. Giger UF, Michel JM, Opitz I, Th Inderbitzin D, Kocher T, Krähenbühl L (2006) Risk factors for perioperative complications in patients undergoing laparoscopic cholecystectomy: analysis of 22,953 consecutive cases from the Swiss Association of Laparoscopic and Thoracoscopic Surgery database. J Am Coll Surg 203(5):723-728

13. Kanaan SA, Murayama KM, Merriam LT, Dawes LG, Prystowsky JB, Rege RV, Joehl RJ (2002) Risk factors for conversion of laparoscopic to open cholecystectomy. J Surg Res 106(1):20-24

14. Borzellino G, Sauerland S, Minicozzi AM, Verlato G, Di Pietrantonj C, de Manzoni G, Cordiano C (2008) Laparoscopic cholecystectomy for severe acute cholecystitis. A meta-analysis of results. Surg Endosc 22(1):8-15

15. Yol S, Kartal A, Vatansev C, Aksoy F, Toy H (2006) Sex as a factor in conversion from laparoscopic cholecystectomy to open surgery. JSLS 10(3):359-363

16. Brodsky A, Matter I, Sabo E, Cohen A, Abrahamson J, Eldar S (2000) Laparoscopic cholecystectomy for acute cholecystitis: can the need for conversion and the probability of complications be predicted?. A prospective study. Surg Endosc 14(8):755-760

17. Lau H, Lo Y, Patil NG, Yuen WK (2006) Early versus delayedinterval laparoscopic cholecystectomy for acute cholecystitis. A meta-analysis. Surg Endosc 20(1):82-87
18. Siddiqui T, MacDonald A, Chong PS, Jenkins JT (2008) Early versus delayed laparoscopic cholecystectomy for acute cholecystitis : a meta-analysis of randomized clinical trials. Am J Surg 195(1):40-47

19. Nuzzo G, Giuliante F, Giovannini I, Ardito F, D'Acapito F, Vellone M, Murazio M, Capelli G (2005) Bile duct injury during laparoscopic cholecystectomy: results of an Italian national survey on 56591 cholecystectomies. Arch Surg 140(10):986-992

20. Regöly-Mérei J, Ihász M, Szeberin Z, Sándor J, Máté M (1998) Biliary tract complications in laparoscopic cholecystectomy. A multicenter study of 148 biliary tract injuries in 26,440 operations. Surg Endosc 12(4):294-300

21. Flum DR, Koepsell T, Heagerty P, Sinanan M, Dellinger EP (2001) Common bile duct injury during laparoscopic cholecystectomy and the use of intraoperative cholangiography: adverse outcome or preventable error? Arch Surg 136(11):1287-1292

22. Suter M, Meyer A (2001) A 10-year experience with the use of laparoscopic cholecystectomy for acute cholecystitis: is it safe ? Surg Endosc 15(10):1187-1192

23. Nakajima J, Sasaki A, Obuchi T, Baba S, Nitta H, Wakabayashi G (2009) Laparoscopic subtotal cholecystectomy for severe cholecystitis. Surg Today 39(10):870-875

24. Tian Y, Wu SD, Su Y, Kong J, Yu H, Fan Y (2009) Laparoscopic subtotal cholecystectomy as an alternative procedure designed to prevent bile duct injury: experience of a hospital in northern China. Surg Today 39(6):510-513

25. Horiuchi A, Watanabe Y, Doi T, Sato K, Yukumi S, Yoshida M, Yamamoto Y, Sugishita H, Kawachi K (2008) Delayed laparoscopic subtotal cholecystectomy in acute cholecystitis with severe fibrotic adhesions. Surg Endosc 22(12):2720-2723

26. Hubert C, Annet L, van Beers BE, Gigot JF (2010) The "inside approach of the gallbladder" is an alternative to the classic Calot's triangle dissection for a safe operation in severe cholecystitis. Surg Endosc 24(10):2626-2632

27. Beldi G, Glättli A (2003) Laparoscopic subtotal cholecystectomy for severe cholecystitis. Surg Endosc 17(9):1437-1439

28. Johansson M, Thune A, Nelvin L, Stiernstam M, Westman B, Lundell L (2005) Randomized clinical trial of open versus laparoscopic cholecystectomy in the treatment of acute cholecystitis. Br J Surg 92(1):44-49

29. Kim JH, Kim JW, Jeong IH, Choi TY, Yoo BM, Kim JH, Kim MW, Kim WH (2008) Surgical outcomes of laparoscopic cholecystectomy for severe acute cholecystitis. J Gastrointest Surg 12(5):829-835 